\title{
Phenotypic and genetic variability of morphometrical traits in natural populations of Drosophila melanogaster and $D$ simulans. I. Geographic variations
}

\author{
P Capy ${ }^{*}$, E Pla, JR David \\ Centre National de la Recherche Scientifique, \\ Laboratoire de Biologie et Génétique Évolutives, 91198 Gif-sur-Yvette Cedex, France
}

(Received 30 March 1993; accepted 10 August 1993)

\begin{abstract}
Summary - Geographical variability between natural populations of the 2 related cosmopolitan species Drosophila melanogaster and $D$ simulans was investigated on a large number of populations (ie 55 and 25, respectively) for 6 morphometrical traits concerning weight, size, reproductive capacity and bristle numbers. For 21 populations, sympatric samples of the 2 species were available. For most traits, the mean values of $D$ melanogaster are higher than those of $D$ simulans, with the exception of the sternopleural bristle number, for which the species are similar. In $D$ melanogaster, similar latitudinal variations exist along an African-European axis, in both hemispheres, and on the American continent. In $D$ simulans, a latitudinal cline that is parallel to those observed in $D$ melanogaster was observed suggesting that variability between populations is partially adaptive. In addition to these parallel variations, in which the mean values of all traits increase with latitude, inter-continental variations were also detected in $D$ melanogaster when populations sampled at similar latitudes were compared (eg, West Indian and Far Eastern populations). Different demographic strategies ( $r$ or $K$ ) could explain such variations. Analysis of morphological distances (Mahalanobis generalized distance $D^{2}$ ) between populations of the 2 species, showed that $D$ melanogaster is much more diversified than $D$ simulans. All the traits except the sternopleural bristle number are involved in these differences.
\end{abstract}

Drosophila melanogaster / Drosophila simulans / morphometrical trait / geographic variability / isofemale line

Résumé - Variabilité phénotypique et génétique de caractères morphologiques dans les populations naturelles de Drosophila melanogaster et de Drosophila simulans. I. Variabilité géographique. La variabilité géographique entre populations naturelles des 2 espèces cosmopolites affines Drosophila melanogaster et $\mathrm{D}$ simulans a été analysée sur un

* Correspondence and reprints 
grand nombre de populations (55 et 25 respectivement), pour 6 caractères morphologiques liés au poids, à la taille, à la capacité de reproduction et aux nombres de soies. Pour 21 populations, un échantillon des 2 espèces était disponible. Sur l'ensemble des caractères, $\mathrm{D}$ simulans présente des moyennes plus faibles que $\mathrm{D}$ melanogaster, à l'exception du nombre de soies sternopleurales pour lequel les 2 espèces sont identiques. Che $z \mathrm{D}$ melanogaster, des variations latitudinales similaires existent le long d'un axe Afrique-Europe, de part et d'autre de l'équateur, et sur le continent américain. Pour D simulans, un cline latitudinal parallèle à ceux détectés chez $\mathrm{D}$ melanogaster a été observé suggérant qu'une partie des variations interpopulations est de nature adaptative. En plus de ces variations parallèles où les moyennes de l'ensemble des caractères augmentent avec la latitude, des variations inter-continentales ont été décelées chez $\mathrm{D}$ melanogaster si l'on compare des populations échantillonnées sur différents continents à des latitudes comparables (populations des Antilles et d'Extrême-Orient). Des différences de stratégies démographiques ( $r$ ou $K$ ) pourraient expliquer ce type de variations. L'analyse des distances morphologiques $\left(D^{2}\right.$ de Mahalanobis) entre les populations au sein de chacune des 2 espèces montre que $\mathrm{D}$ melanogaster est globalement bien plus diversifiée que $\mathrm{D}$ simulans pour l'ensemble des caractères à l'exception du nombre de soies sternopleurales.

Drosophila melanogaster / Drosophila simulans / caractères morphométriques / variabilité géographique / lignées isofemelles

\section{INTRODUCTION}

The sibling species Drosophila melanogaster and $D$ simulans present strong morphological similarities. They were often confused until Sturtevant (1919) described $D$ simulans as a close relative of $D$ melanogaster. These 2 cosmopolitan species are widely distributed in both temperate and tropical regions. However, while they are sympatric in many places, their relative proportions are not always the same. For instance, in Africa, the relative proportion of the 2 species exhibits a geographic gradient from the Ivory Coast, where $D$ simulans is almost absent and $D$ melanogaster is the main species, to islands in the Indian Ocean close to the African coast where $D$ simulans is more abundant than $D$ melanogaster (Lachaise et al, 1988). Moreover, $D$ simulans is not found in several countries in the Far East, or has been recently introduced there.

At first it was expected that because of their common ancestry, the 2 species would exhibit similar patterns in the genetic variability of their natural populations. During the last 2 decades, they have been compared for numerous kinds of traits, including: chromosomal inversions (Ashburner and Lemeunier, 1976; Lemeunier et al, 1986); mitochondrial DNA (Solignac and Monnerot, 1986; Hale and Singh, 1985); enzymatic polymorphism (Hyytia et al, 1985; Singh et al, 1987; Singh, 1989; Choudhary and Singh, 1987); dispersed repetitive DNA (Dowsett and Young, 1982); protein polymorphism analysed by 2-dimensional electrophoresis (Ohnishi et al, 1982, Choudhary et al, 1992); physiological traits (Parsons 1983; David et al, 1983); behavioural traits (Cobb et al, 1985, 1986, 1987); cuticular hydrocarbons (Jallon and David, 1987); and morphological traits (Tantawy and Mallah, 1961; David and Bocquet, 1975; Parsons, 1983; Hyytia et al, 1985). 
In most of these analyses, it was found that $D$ melanogaster has greater variability between populations than $D$ simulans. Only 2 exceptions can be mentioned. First, $D$ simulans was found to be 3 times more variable than $D$ melanogaster for the interpulse interval (IPI) of courtship song, (Kawanishi and Watanabe, 1981). Second, at the DNA level, the restriction-site polymorphism was greater in $D$ simulans in the rosy region (Aquadro et al, 1988) and in regions on the $\mathrm{X}$ chromosome including the $y, P g m$ and per genes (Begun and Aquadro, 1991).

Although the 2 species were compared for many traits, few morphological data are available. In the works cited above that deal with these quantitative traits, the geographical variability between natural populations of $D$ melanogaster and $D$ simulans was investigated in a restricted area and from a small number of populations. Moreover, according to their different authors, investigations were carried out under different laboratory conditions making comparisons difficult or impossible. Therefore, only tendencies were evidenced, from these data, and it was difficult to draw general conclusions.

The aim of this work is to compare the geographical variability of $D$ melanogaster and $D$ simulans from natural populations collected in various parts of the world. Two related questions will be considered; i) how much geographical variability is found in the 2 species and ii) whether the patterns found for morphometrical traits match those observed for other genetic traits.

To answer these questions, the variability between populations (this paper) and the within-population variability (Part II, Capy et al, 1994) were investigated for 6 morphological traits. These traits can be clustered as follows: traits related to size (weight, wing and thorax lengths); a trait related to the reproductive capacity (ovariole number); and 2 bristle numbers. The first 2 types of traits are likely under selective pressures in natural conditions, while bristle numbers are generally considered as more neutral.

Such a diversity of characters allows various comparisons of the 2 species. From selected traits, it is possible to determine whether general rules of geographical variations exist and thus which geographical or climatic related factors are involved. On the other hand, the genetic variability observed between populations for neutral traits could be partly due to genetic drift. It is also interesting to compare the 2 species for complex traits involving a large number of genes, such as fresh weight, and for traits determined by a few major genes, such as bristle number (Shrimpton and Robertson, 1988a, 1988b).

In this work, we found that while latitudinal clines exist in both species, natural populations of $D$ melanogaster are much more differentiated than those of $D$ simulans for all traits with the exception of the sternopleural bristle number. These results are compared with those obtained for other traits, and the hypotheses already proposed to explain the differences between the 2 species are discussed according to our data. 


\section{MATERIALS AND METHODS}

\section{Natural populations}

Fifty-five natural populations of $D$ melanogaster and 25 of $D$ simulans were analysed; 21 populations of each species were sympatric (table I). All populations originated from low altitudes and were collected with attractive fermenting fruit traps. In all cases, isofemale lines were used, $i e$ wild inseminated females were isolated in culture vials to produce progeny. Because wild females may be inseminated by more than 1 male (Milkman and Zietler, 1974), the following procedure was used. One male and 1 female from 2 different initial lines were mated to initiate a new line. These parents were transferred to a highly nutritive food (killed yeast medium, David and Clavel, 1965). To avoid crowding effects, a maximum of 50 eggs were reared in the same tube and the emergences (full-sib individuals) were used for the morphological analyses. Thus, from $n$ initial lines, $n / 2$ new lines were produced and 10 individuals per line were measured. In some cases, the new lines were generated and studied after the initial lines had been kept in the laboratory for a few generations (generally, less than 5).

Table I. Mean values and standard error of the means of the 6 morphological traits ${ }^{\mathrm{a}}$.

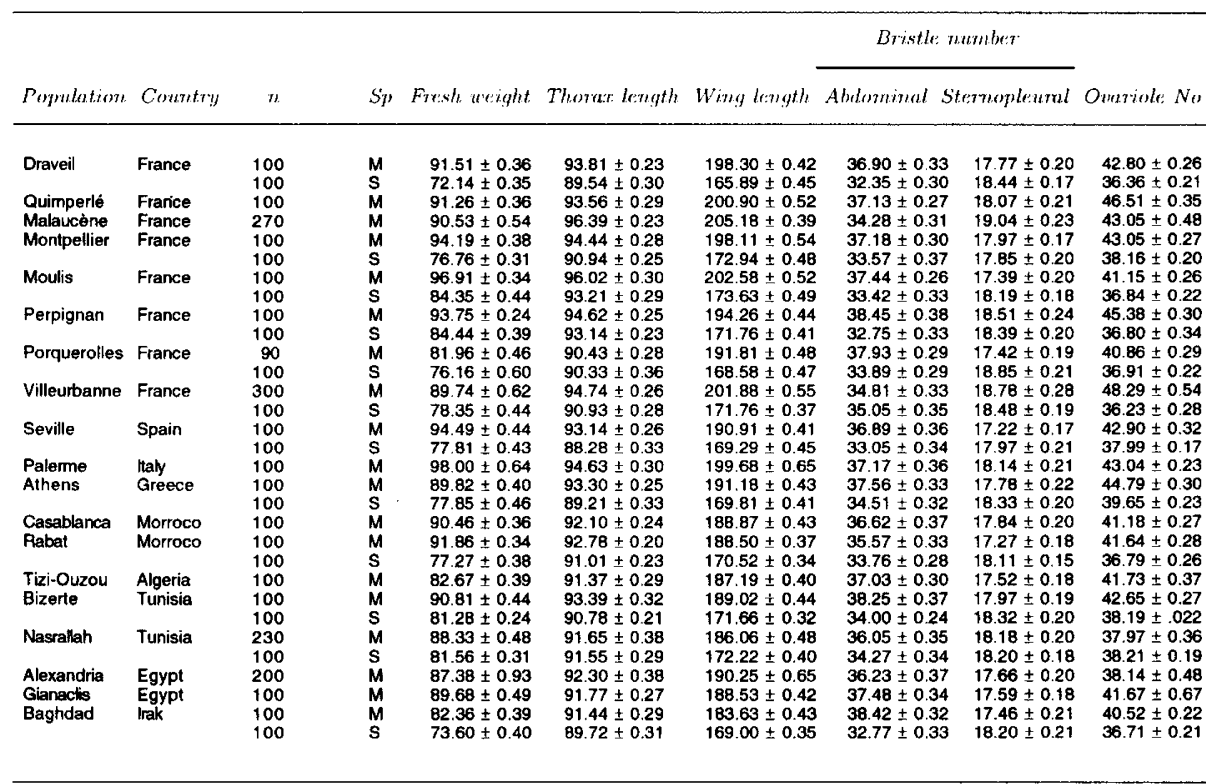


Table I. (Continued)

Bristle number

Population Country $\quad{ }_{n} \quad$ Sp Frysh ueight Thonax length Wing length Abdominal Stemopleurral Ouariole No

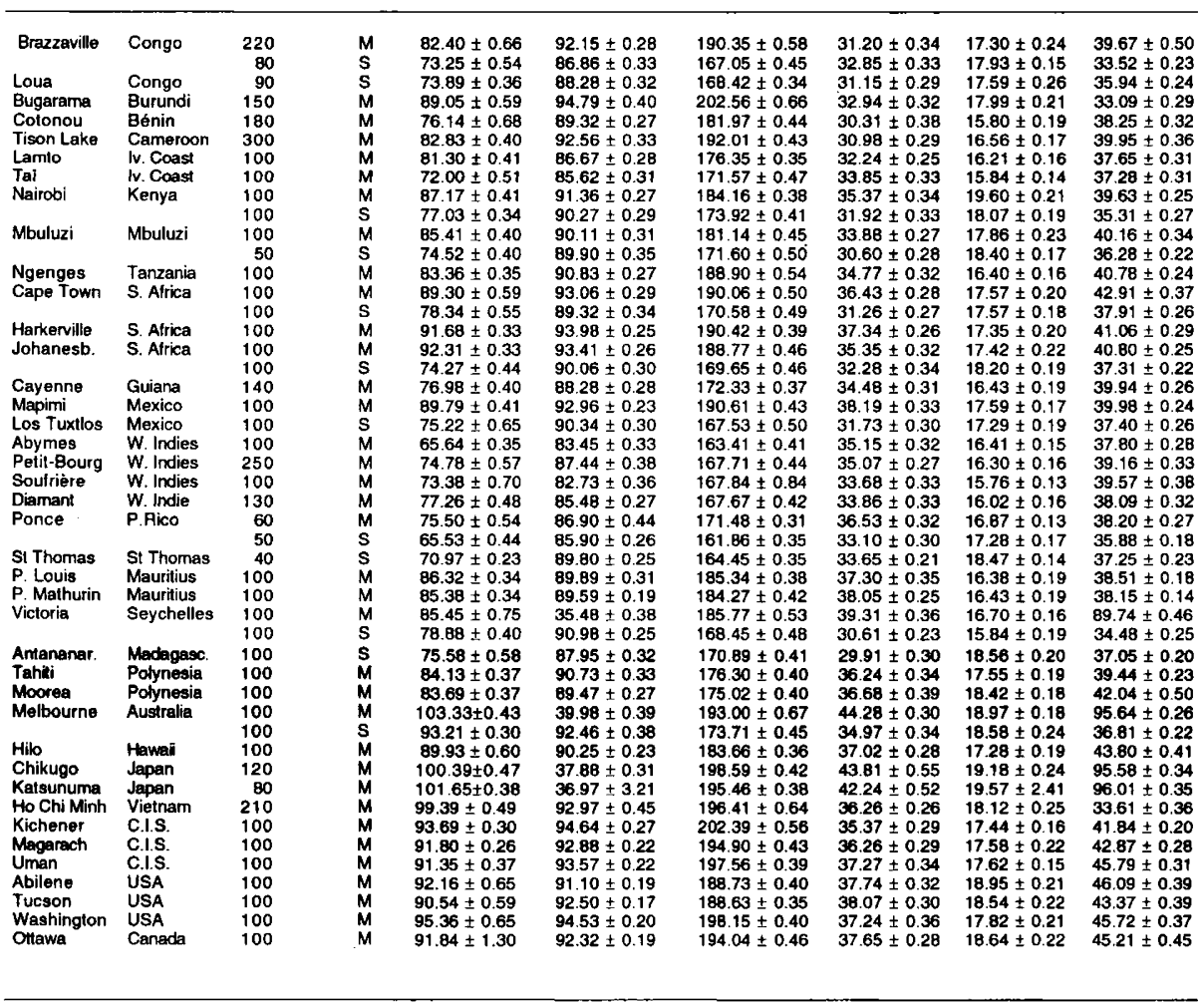

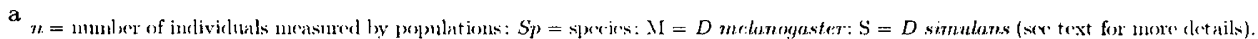

\section{Morphological traits}

Six morphometrical traits were considered: fresh weight $(F W)$ measured a few hours after emergence (expressed in $\mathrm{mg} \times 100$ ); the sum of the abdominal bristles on the fourth and fith tergites $(A B)$; the sum of the sternopleural bristles on the right and left sides $(S B)$; the thoracic length $(T L)$ in lateral view (expressed in $\mathrm{mm} \times 100)$; wing length $(W L)$ measured between the humeral cross-vein and the tip of the third longitudinal vein (expressed in $\mathrm{mm} \times 100$ ); and the total ovariole number $(O N)$ of both ovaries (David, 1979). Since a high correlation exists between males and females of the same line (David et al, 1977; Capy 1987) measurements were made on 1 sex, ie males for the morphology and females for ovariole number. 


\section{Geographic diversity}

Morphological distances between natural populations were estimated by the Mahalanobis generalized distance $\left(D^{2}\right)$ over the 6 traits considered here. This is a Euclidian distance based on the generalized Pythagoras theorem and related to the Hoteling $T^{2}$ used in discriminant analysis. The Mahalanobis distance was calculated using the mean values of each isofemale line as basic data. To visualize the difference of morphological variability between the 2 species, some trees based on the matrices of the distance are proposed. These trees were built using PHYLIP (version 2.9). To this end, populations were clustered into several groups according to their geographic proximity. For $D$ melanogaster, 13 groups were considered: France, CIS (ex USSR); East Mediterranean; West Mediterranean; Tropical Africa; the Seychelles and the Mascarene Islands; Southern Africa; North America (northern USA and Canada); West Indies; southern USA and Mexico; the Society Islands and Hawaii; the Far East; and Australia. For D simulans, only 8 groups were considered: France; East Mediterranean; West Mediterranean; Tropical Africa, South Africa; French West Indies; Southern USA and Mexico; and the Seychelles and the Mascarene Islands.

Latitudinal variations of the 6 morphometrical traits were mainly analysed along a transect between tropical Africa and Europe. For $D$ melanogaster both hemispheres and a transect between Mexico and North America were also considered. For this species, intercontinental variations between America, North Africa and Far East were also analysed.

\section{RESULTS}

Table I gives the mean values of the 6 quantitative traits for all the populations sampled. This table will be analysed according to 3 main points: general trends of the between population variability in both species, and geographical variations according to either latitude or different continents.

\section{General trends}

Table I shows that $D$ melanogaster values are generally higher than those of $D$ simulans. However, due the broad range of variation found in each species, some overlaps can be found. For example, male fresh weight in French $D$ simulans (eg, 84.44 in Perpignan) may be much higher than the same trait in African $D$ melanogaster (eg, 76.14 in Cotonou). A better comparison is provided when only the sympatric populations are compared (table II).

As shown in table II, the overall mean values are statistically inferior in $D$ simulans than in $D$ melanogaster, with the exception of the number of sternopleural bristles. A detailed analysis of table I shows that this is a general phenomenon when sympatric populations are compared. Mean values of $D$ melanogaster are always higher for $F W, T L, W L$ and $O N$; all these traits are related to size or reproduction. $D$ simulans is then smaller with a lower reproductive capacity than $D$ melanogaster. This confirms results already observed in a few populations in different parts of the world (Tantawy and Mallah, 1961; David and Bocquet, 1975). 


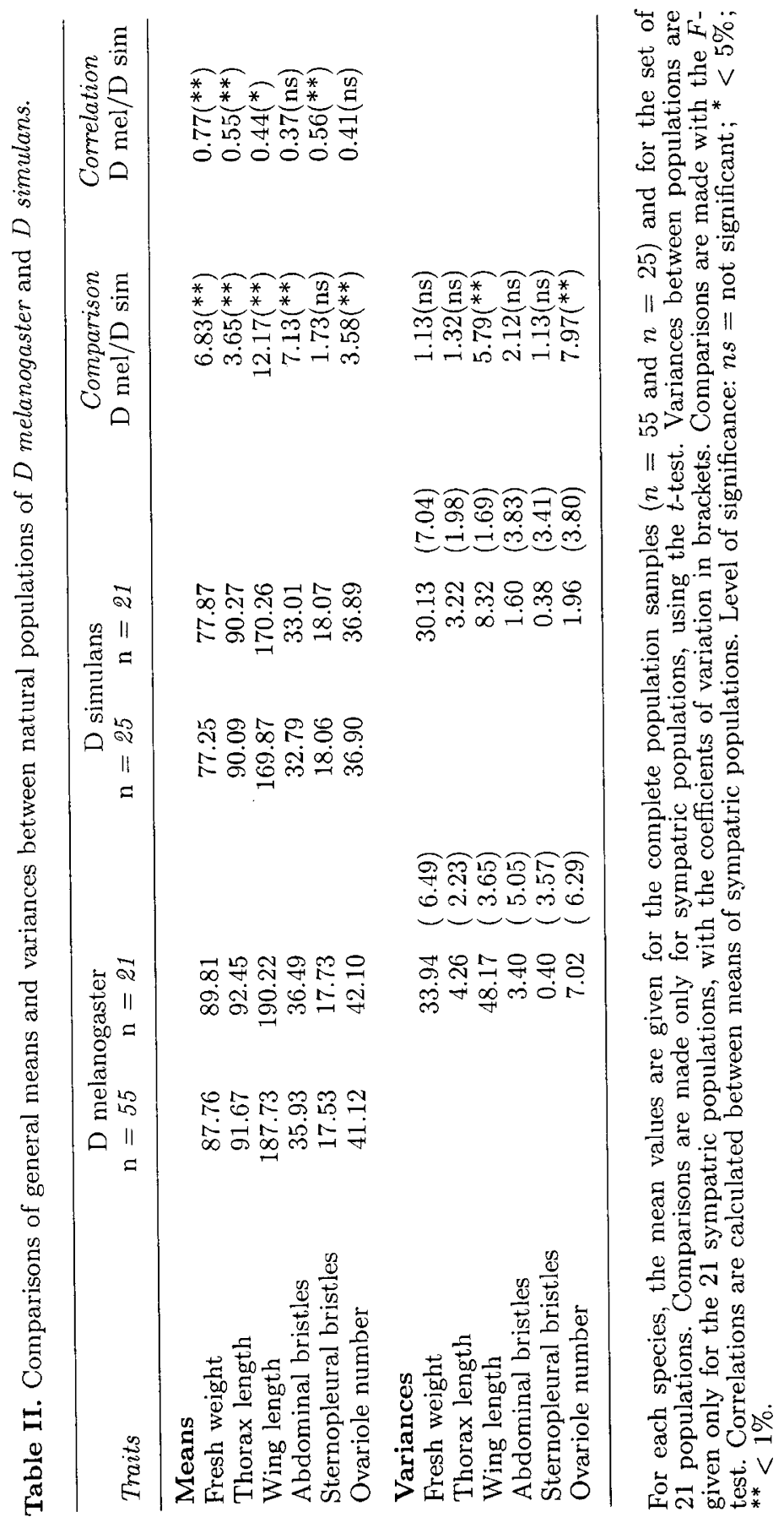


The 2 species are quite similar for the thorax length (92.45 for $D$ melanogaster versus 90.27 for $D$ simulans) while wing length, fresh weight and ovariole number are substantially different (190.22 versus $170.26 ; 89.81$ versus 77.87 ; and 42.10 versus 36.89 ). The conformation and the shape of individuals are therefore different in the 2 species and their respective wing loads are not exactly the same.

Variances between populations (table II) are mainly due to long-range geographic variations. In all cases, they are higher in $D$ melanogaster than in $D$ simulans but only 2 are statistically significant for wing length and ovariole number. This is a first indication that different traits do not exactly follow the same rules of variation in the 2 species. For example, wing length is far more variable in $D$ melanogaster than in $D$ simulans and thorax length exhibits a similar pattern.

For each morphological trait, correlations between mean values of sympatric populations are positive, and 4 out of 6 are significant (table II). Such a result evidences parallel variations in the 2 species and suggests an adaptive significance.

\section{Geographic variability}

Morphological distances between natural populations of each species were estimated by the Mahalanobis $D^{2}$, taking into account simultaneously the 6 traits. The distributions of this distance are given for the 2 species in figure 1 . The differences between $D$ melanogaster and $D$ simulans are clear both when all (white histograms) or only sympatric (black histograms) populations are considered. A representation is given in figure 2, in which populations have been clustered according to their geographical origin (Materials and methods). The trees show that the distances between populations within each species are clearly different (compare the 2 trees on the same scale), but the classification of populations are roughly the same. All the morphological traits studied here are involved in the differentiation of the 2 species with the exception of the sternopleural bristle number.

For $D$ melanogaster, 3 main groups of populations can be distinguished: populations of temperate regions including northern USA, Canada, France and ex-USSR; populations of tropical regions including the West Indies, the Society Islands and Hawaii ; and populations in tropical Africa, the Seychelles and the Mascarene islands. Between these 3 main groups, we find populations living in regions with intermediate climates such as South Africa, Mediterranean countries, southern USA and Mexico, the Far East and Australia.

For $D$ simulans, 3 types of region are found, ie tropical regions, Mediterranean countries and Australia. However, it must be stressed that for this species, temperate countries were represented only by French populations; these populations mainly originated in southern France thus explaining why they are close to Mediterranean populations.

\section{Latitudinal clines}

Most of the populations studied here belong to an African-European transect from South Africa to France. For $D$ melanogaster, similar latitudinal clines are observed when the 2 hemispheres are considered independently. In both cases, the mean values of all traits significantly increase with latitude from the equator to higher northern or southern latitudes (table III). 


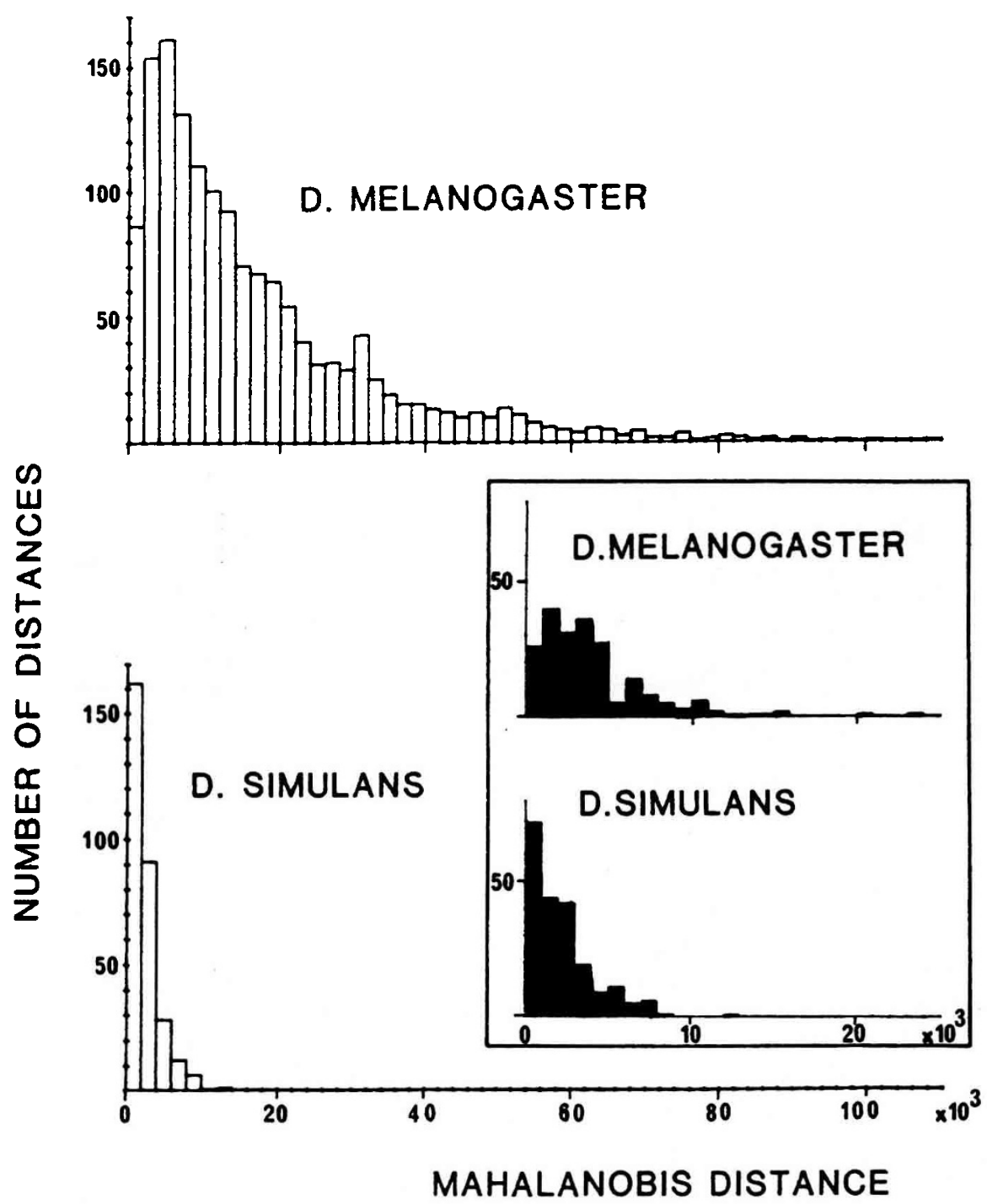

Fig 1. Distributions of generalised distances of Mahalanobis $\left(D^{2}\right)$. White distributions correspond to the distances calculated over the total populations available in each species. Black distributions correspond to the distances calculated between the 21 sympatric populations.

On the north American continent, although only 11 populations were available, a latitudinal cline showing the same tendencies for all traits was also observed. All the correlations between mean values and latitude are significantly positive. Therefore, the clines on the American continent and along the African-European 


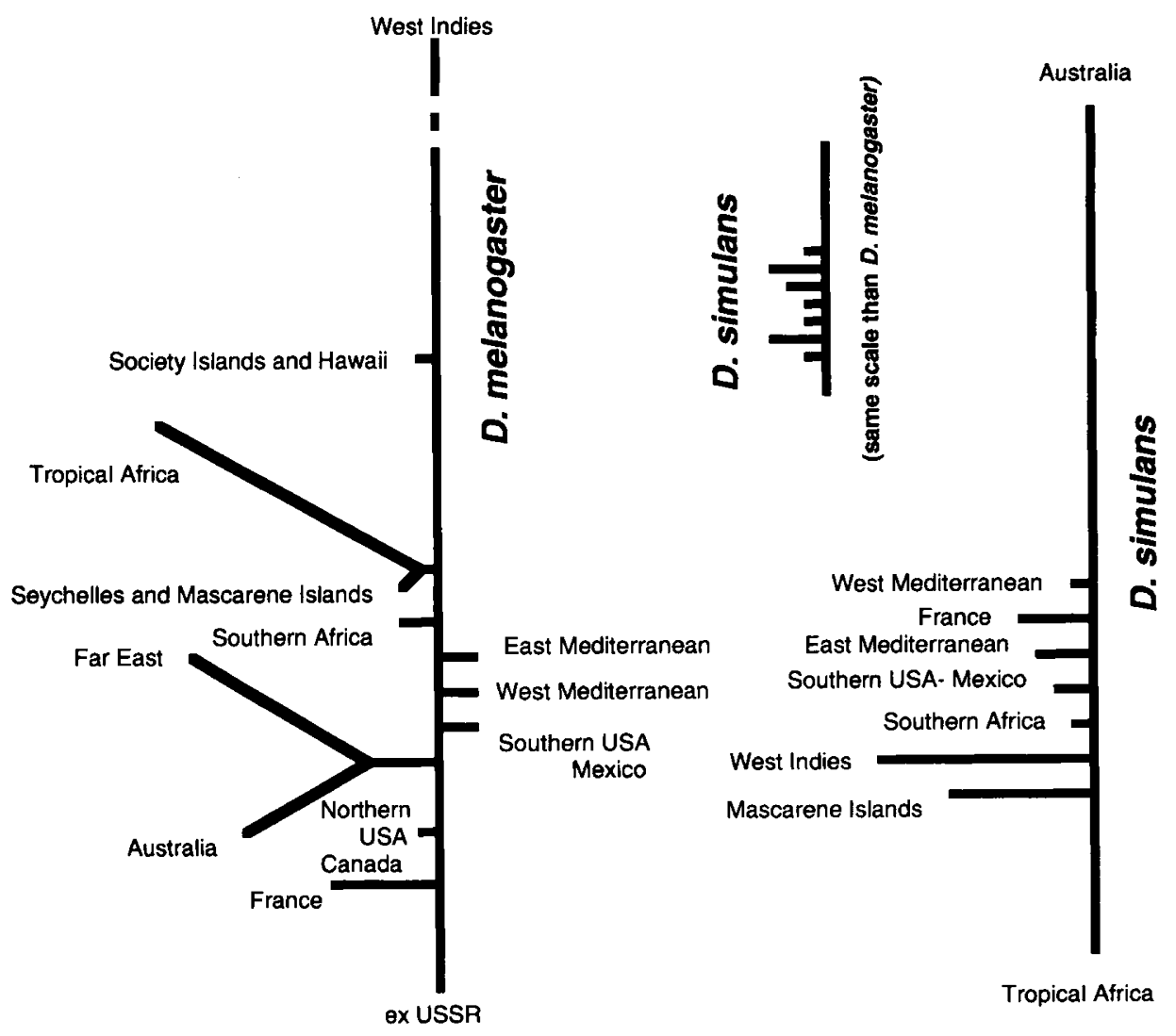

Fig 2. Trees built from the matrices of morphological distances with the program PHYLIP (version 2.9). To this end, populations were clustered according to their geographical origins, ie 10 groups for $D$ melanogaster and 9 groups for $D$ simulans.

axis are parallel. As an example, the relationship between latitude and ovariole number is given in figure 3 for the whole set of 55 populations.

For $D$ simulans, only the African-European axis was considered, with 19 populations. All the correlations with latitude are positive but only 3 are significant. However, when all the populations sampled are considered all the correlations with latitude become significant.

Latitudinal variations may also be analysed simultaneously by combining the 6 morphometrical traits in a principal component analysis. The results obtained for $D$ melanogaster along the European-African transect are shown in figure 4 . Axis 1 is mostly related to latitude and we see that South African populations are close to those in the Mediterranean. Significant differences are also expressed on the second axis, especially for the populations of Mauritius and the Seychelles. The population of the Seychelles is close to populations of Mediterranean countries and tropical 
Table III. Correlations between mean values and latitude for the six morphological traits. The sets of populations considered here are the following: I from Southern Africa to Europe; II from Guiana to Canada; III all populations.

\begin{tabular}{|c|c|c|c|c|c|}
\hline \multirow[b]{2}{*}{ Traits } & \multicolumn{3}{|c|}{ D melanogaster } & \multicolumn{2}{|c|}{ D simulans } \\
\hline & $\begin{array}{c}I \\
\mathrm{n}=37\end{array}$ & $\begin{array}{c}I I \\
\mathrm{n}=11\end{array}$ & $\begin{array}{c}I I I \\
\mathrm{n}=55\end{array}$ & $\begin{array}{c}I \\
\mathrm{n}=19\end{array}$ & $\begin{array}{c}I I I \\
\mathbf{n}=25\end{array}$ \\
\hline Fresh weight & $0.61\left({ }^{* *}\right)$ & $0.82\left(^{* *}\right)$ & $0.59\left(^{* *}\right)$ & $0.31(\mathrm{~ns})$ & $0.39(* *)$ \\
\hline Thorax length & $0.60\left(^{* *}\right)$ & $0.79\left(^{* *}\right)$ & $0.60\left(^{* *}\right)$ & $0.44(\mathrm{~ns})$ & $0.48\left(^{* *}\right)$ \\
\hline Wing length & $0.47\left(^{* *}\right)$ & $0.85\left(^{* *}\right)$ & $0.61\left(^{* *}\right)$ & 0.15 (ns) & $0.31\left(^{*}\right)$ \\
\hline Abdominal bristles & $0.62\left(^{* *}\right)$ & $0.75\left(^{* *}\right)$ & $0.62\left(^{* *}\right)$ & $0.61\left(^{* *}\right)$ & $0.54\left(*^{* *}\right)$ \\
\hline Sternopleural bristles & $0.70(* *)$ & $0.87\left(^{* *}\right)$ & $0.62\left(^{* *}\right)$ & $0.58\left(^{*}\right)^{\prime}$ & $0.50(* *)$ \\
\hline Ovariole number & $0.67\left(^{* *}\right)$ & $0.85\left(^{* *}\right)$ & $0.73(* *)$ & $0.66\left(^{* *}\right)$ & $0.60\left(^{* *}\right)$ \\
\hline
\end{tabular}

$n=$ number of populations; level of significance: $n s=$ not significant; ${ }^{*}<5 \% ;{ }^{*}<1 \%$.

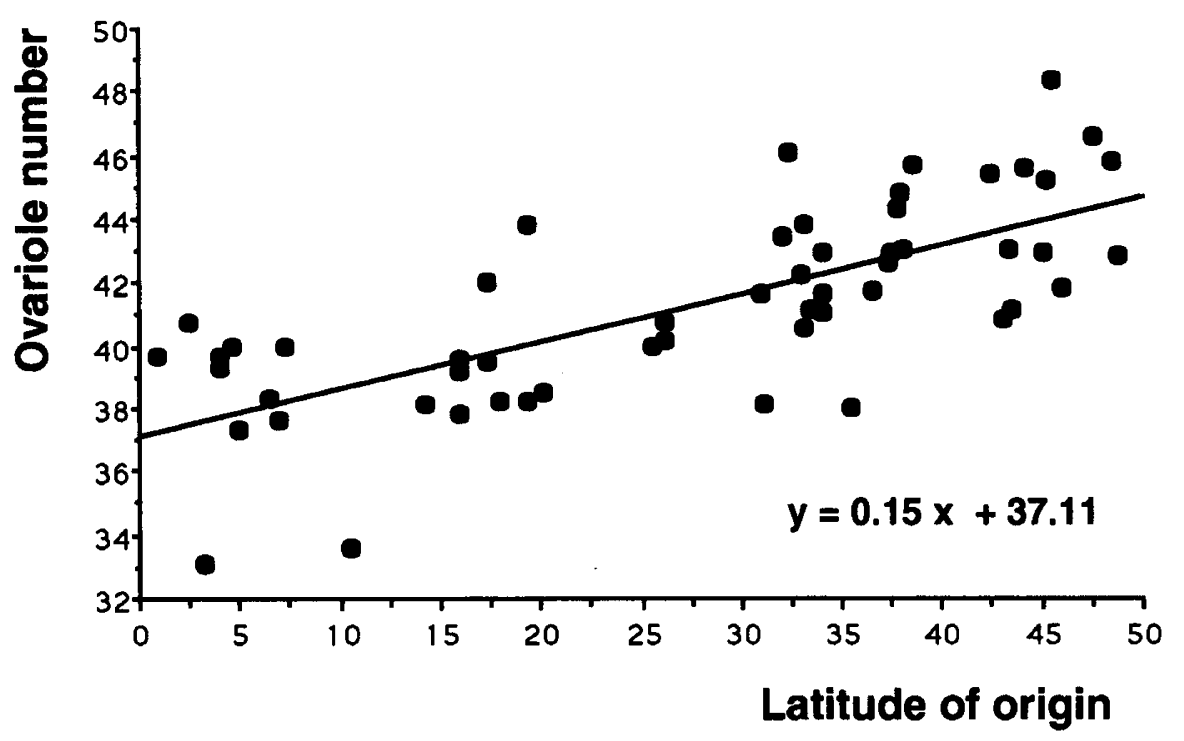

Fig 3. Latitudinal variations of the ovariole number in $D$ melanogaster. Each point corresponds to the mean value of each natural population. All 55 populations were considered whatever their geographical origins.

Africa. Historical evidence suggests that $D$ melanogaster was recently introduced into the Seychelles archipelago (David and Capy, 1982) but the geographical origin of colonising populations remains unknown. From the analysis of allozymes frequencies and ethanol tolerance, this population is almost identical to European populations. On the other hand, from biometrical traits, this population remains intermediate between temperate and tropical populations, even though the Seychelles are close to the equator. Figure 4 suggests that this population might come 


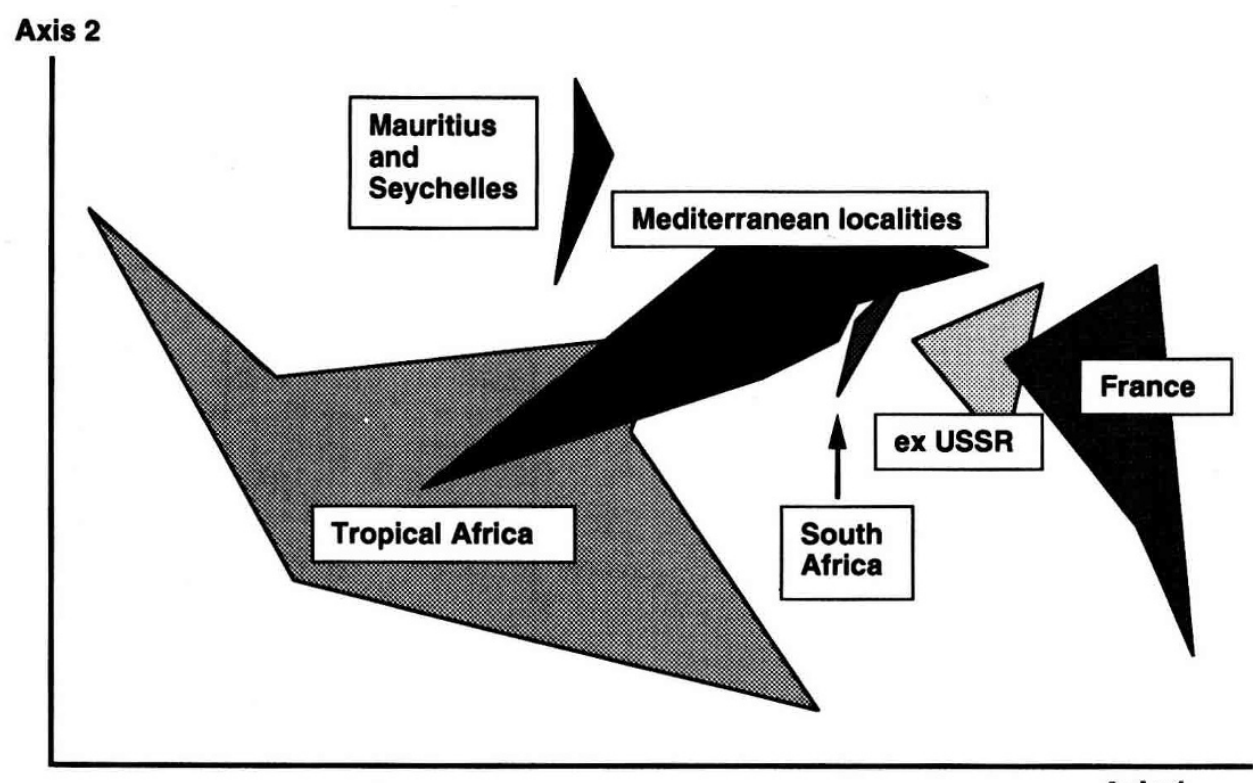

\section{Axis 1}

Fig 4. Projection on the first 2 axes of a principal component analysis of natural populations of $D$ melanogaster belonging to the African-European latitudinal transect. Populations were clustered according to their proximity. This plane explains $78 \%$ of the total variance. All morphological traits are highly correlated with the first axis while only the abdominal bristle number is correlated with the second axis.

from either Mediterranean or South African populations. Its intermediate position could also reflect a partial adaptation to a new tropical environment.

\section{Variability between continents}

In $D$ melanogaster, although parallel latitudinal clines are evidenced on 2 continents, populations from the same latitude but different continents do not show similar morphological characteristics. For instance, when tropical populations are ordered along a longitudinal gradient, from the West Indies to tropical Africa and the Far East, significant differences are observed for fresh weight, thorax and wing lengths and ovariole number. For the first 3 traits, the mean values increase from West Indian to Far Eastern populations (fig 5 ) while the mean values of ovariole number decrease. In other words, individuals in the West Indies are lighter and smaller than those in the Far East, but they also have a higher reproductive capacity; African populations are intermediate for all these traits.

\section{Correlations with climatic factors}

Previous observations often suggest that geographical variability reflects adaptive responses to local environment. To check whether a simple climatic factor was related to geographical variability of morphology, 8 climatic parameters were considered. Four of these were related to temperature (average temperature of the 


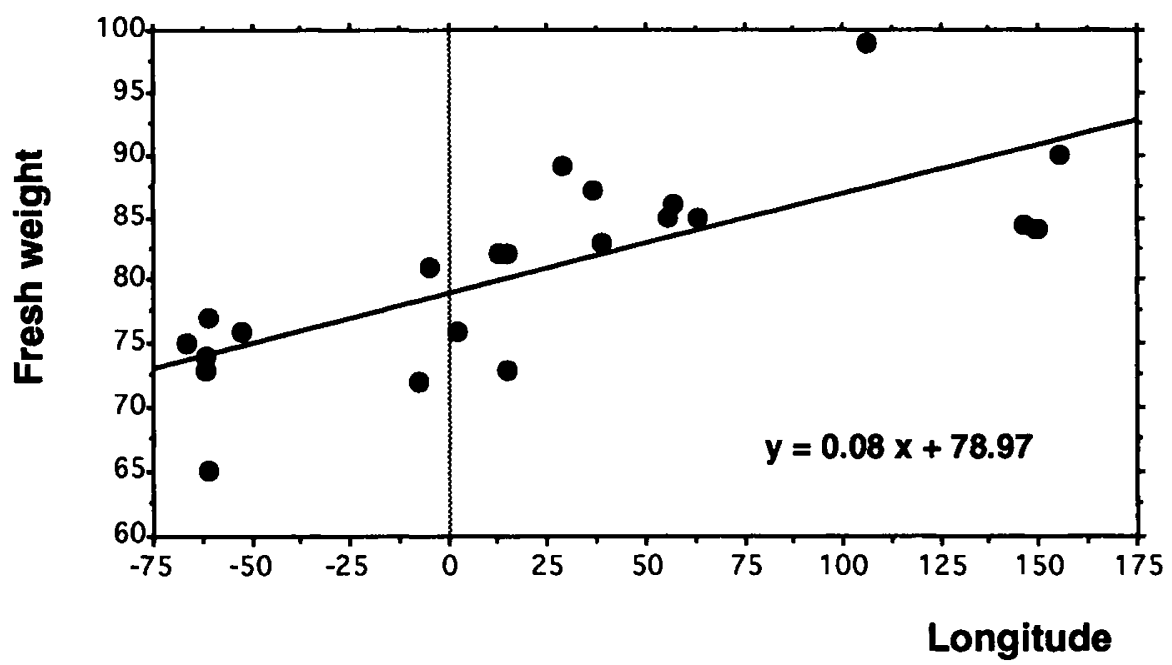

Fig 5. Variations of average values of fresh weight according to longitude in $D$ melanogaster. Only populations belonging to a latitudinal range between the 20th north parallel and the 20th south parallel were considered. Populations were ordered from Caribbean to Pacific islands.

hottest and coldest months, the difference between these 2 values and the average temperature of the year). The 4 remaining parameters were related to rainfall (average total rainfall of the wettest and dryest months, the difference between these 2 values and average total rainfall of the year). These data were taken from the World Meteorological Organisation (1982) and correspond to average values over a period of at least 10 years. Because most climatic parameters were highly correlated with latitude (in general $p<0.001$ ), partial correlations (to subtract the latitudinal effect) between climatic data and morphometrical traits were calculated. Few partial correlations remain significant but none of the correlations observed for $D$ melanogaster exist in $D$ simulans.

\section{DISCUSSION AND CONCLUSION}

\section{Is geographic variability adaptive?}

Our results from a large number of natural populations show that $D$ melanogaster is geographically much more diversified than $D$ simulans. In $D$ melanogaster, similar variations are observed in different hemispheres or continents and these variations are parallel to those observed in $D$ simulans, with the exception of the sternopleural bristle number.

In $D$ melanogaster, parallel latitudinal clines, observed on the American continent and between tropical Africa and Europe, strongly suggest an adaptive significance of the geographical variability. Another possibility could be that colonisation of the American continent occurred from several populations, already differentiated 
prior to invasion. In other words, the variability observed on this continent could be a transposition of a pre-existing variability. For example, populations of Canada and northern USA could originate from Europe. Those from the West Indies, Mexico and southern USA could originate from tropical Africa. Such a scenario is quite possible since colonisation of the North American continent occurred during the last centuries from different European and African populations (David and Capy, 1988). However, the similar clines in both hemispheres and in the 2 sibling species favour the adaptive hypothesis of the geographical variability. Nevertheless, it is also possible that the colonisation of the American continent from different parts of the world reduced the adaptation time of the colonising populations to their new environment. On the other hand, it must be stressed that adaptation to new environmental conditions can be rapid. In this respect, we should indicate that, after its introduction from Europe to South America (in Chile), D subobscura has been able to establish new latitudinal clines for chromosomal arrangements in less than a decade (Prevosti et al, 1985). Similar phenomena were also observed for alloenzyme frequencies in $D$ simulans a few years after the colonisation of the Japanese islands (Watada et al, 1986).

Existence of a latitude-related morphological variability suggests that selective factors like temperature or rainfall could be involved. A strong negative correlation is observed between latitude and mean annual temperature, the temperature of the coldest month and total annual rainfall. Morphometrical latitudinal clines are thus strongly correlated to these average parameters. We tried to reach more precise conclusions by considering partial correlations and taking out the latitudinal influence, but this analysis failed to produce significant conclusions. Thus, the most significant factors regulating geographical variations appear to be temperature and rainfall. While the role of rainfall is difficult to understand and analyse, the effects of temperature treatments can be investigated in the laboratory. In this respect, several authors including Cavicchi et al (1985) have shown that breeding at different temperatures may induce divergence of wing size and shape. It is likely that such phenomena could be observed for most of the traits related to size as was evidenced by Anderson (1973) in D pseudoobscura. On the other hand, it is also possible that adaptation is not the result of the effect of a single climatic parameter, but could be due to a combination of these factors or to more complex environmental effects, including interspecific competition.

Although latitudinal trends of the geographical variability have been clearly evidenced, some longitudinal variations were also observed. For instance, at a given latitude, populations may be quite different although they apparently share similar environments. Such is the case of the West Indian and Far Eastern populations of $D$ melanogaster. Our results on Far Easten populations are in agreement with those of Teissier (1957) and David et al (1976). These populations are generally heavier than Afrotropical flies and even heavier than European temperate flies. They contrast with West Indies individuals, which are smaller than Afrotropical ones (Capy et al, 1986). Because weight and size may be related to life duration and because the reproductive capacity is also affected in an opposite way, these results suggest that intercontinental variations may reflect different ecological strategies.

According to the terminology of MacArthur and Wilson (1967), populations of Far Eastern countries could be defined as $K$-selected while those of the West 
Indies could be $r$-selected. In other words, West Indian populations develop more rapidly, are smaller and invest less into each offspring while Far Eastern populations develop more slowly, are larger and invest more energy into each individual (Taylor and Condra, 1980 and references therein). Such differences could be the result of different histories and/or local selective pressures. Indeed, according to David and Capy (1988), Far Eastern populations of $D$ melanogaster are ancient (possibly more than 10000 years) while West Indian populations are recent (a few centuries).

Such data are not available for $D$ simulans since this species is absent in several Caribbean islands (David and Capy, 1983), does not exist in most Asian countries and has only recently colonised some parts of Far Eastern countries like Japan (Watanabe and Kawanishi, 1976).

\section{D melanogaster versus D simulans}

To explain the differences in geographical variability between the 2 species several hypotheses have been proposed, mainly by Choudhary and Singh (1987) and Singh et al (1987).

The first hypothesis, based on niche width, suggests that $D$ melanogaster is more diversified than $D$ simulans because of a greater physiological and behavioural flexibility. Therefore, the variability in both species should be an adaptive trait. But, what is the cause and what is the effect? In other words, is the niche width of $D$ melanogaster larger than that of $D$ simulans because of greater genetic variability, or is the variability of $D$ melanogaster higher because of its larger niche width? In natural conditions, few data are available on the niche width of these 2 species. It is only known that $D$ melanogaster is more related to human activities and can be found inside buildings while $D$ simulans remains outside (Rouault and David, 1982; Capy et al, 1987). In temperate countries, $D$ melanogaster is able to use resources with a high ethanol content while $D$ simulans cannot (see Parsons, 1983). Moreover, $D$ melanogaster can be found at higher latitudes than $D$ simulans (Louis, 1983). Finally, in laboratory conditions, many experiments on tolerance to temperature, showed that $D$ melanogaster has a larger spectrum of tolerance (Parsons, 1983; David et al, 1983) suggesting that this species could fit into a larger number of natural situations than its sibling.

Under this hypothesis, morphological variability between and within populations should be higher in $D$ melanogaster. As shown in this paper, such a result is observed at the between-population level. However, for more traits the 2 species have similar levels of phenotypic and genetic variability within the population (see Part II, Capy et al, 1994).

A second hypothesis is that the 2 species have different genetic strategies (Singh et al, 1987). In this respect, $D$ melanogaster would be fine grained while $D$ simulans would be coarse grained or with a general purpose genotype (Singh and Long, 1992). In other words, facing diverse environmental situations, $D$ simulans would have few all-purpose genotypes while $D$ melanogaster would have many genotypes with limited capacities. This hypothesis assumes that the phenotypic plasticity of $D$ simulans should be higher than that of $D$ melanogaster, but is not supported by the previously mentioned experiments on tolerance to several stresses. At the morphological level, the only data available concern the pigmentation of thoracic 
trident (Capy et al, 1988) showing that the phenotypic plasticity of $D$ simulans was inferior to that of $D$ melanogaster. It was also evidenced, however, that the potential genetic variation of $D$ simulans was high since it was possible to select rapidly very dark flies with a pigmentation score higher than that of $D$ melanogaster natural populations.

The third hypothesis, proposed by Singh et al (1987), refers to the recent world expansion of $D$ simulans from a few individuals native to an African ancestral population. This hypothesis is based on the mtDNA polymorphism which is drastically reduced in $D$ simulans compared to $D$ melanogaster (Baba-Aïssa and Solignac, 1984; Hale and Singh, 1985; Solignac and Monnerot, 1986). For morphological traits, this hypothesis raises the question of the time required for a newly arrived population to be adapted to its new environmental conditions. In this respect, the only natural experiment is the recent introduction of $D$ simulans into the main islands of Japan (Watanabe and Kawanishi, 1976). Although the origin of colonisers is not known, in less than 10 years some latitudinal cline were already observed for morphological traits (Watada et al, 1986). According to these authors, the geographical differentiation occurs rapidly for a trait like ovariole number, and at various speeds for other traits depending on their adaptive value. Thus, for traits under high selective pressures, some geographical divergence may rapidly appear. In other words, even if the expansion of $D$ simulans was relatively recent compared with that of $D$ melanogaster (Lachaise et al, 1988), there was enough time for the new population to be adapted to the new environment, at least for some morphological traits.

A fourth hypothesis proposed to explain the difference of geographical variability between the 2 sibling species, is that the mutation rate could be higher in $D$ melanogaster. The main argument in favour of this hypothesis is that the proportion of nomadic sequences is superior in $D$ melanogaster (Dowsett and Young, 1982), such sequences being able to generate chromosomal rearrangements and mutations by insertion or imprecise excision. Singh et al (1987) argued that this hypothesis could not explain the geographical differentiation of the 2 species. On the other hand, it is also assumed that nomadic sequences like transposable elements may be involved in the adaptation of natural populations to the environment (McClintock, 1984; McDonald et al, 1987). Indeed, mobility of transposable elements may create a new variability which can be selected at the morphological level (Mackay, 1984; Pignatelli and Mackay, 1989). Concerning the diversity of transposable elements already described, the 2 species are not so different. Although $D$ melanogaster has been more extensively studied, most of the elements are present in both species, with a few exceptions including $P$ and mariner (Brookfield et al, 1984; Maruyama and Hartl, 1991). It is not known, however, whether the elements have different mobilities in the 2 species. Inoue and Yamamoto (1987) showed that the mutation rate by insertion of mobile elements in the white gene of $D$ simulans, was similar to that observed in $D$ melanogaster, suggesting that the 2 species have similar potential variability.

In conclusion, and in spite of several hypotheses, some of them being not mutually exclusive, the differences between the 2 species remain difficult to explain. In all cases, it must be stressed that there is still a lack of information about the ecology and the population structure of these species. Moreover, in most of the 
work previously published, the geographical variability was mainly considered while the within-population component remained poorly investigated. It is not known whether the potential for variability is the same in the 2 species and whether these potentialities are expressed and used in similar ways. This problem is considered in Part II (Capy et al, 1994).

\section{REFERENCES}

Aquadro CF, Lado KM, Noon WA (1988) The rosy region of Drosophila melanogaster and Drosophila simulans. I. Contrasting levels of naturally occurring DNA restriction map variation and divergence. Genetics $119,875-888$

Anderson WW (1973) Genetic divergence in body size among experimental populations of Drosophila subobscura kept a different temperatures. Evolution 37, 278-284 Ashburner M, Lemeunier F (1976) Relationship within the melanogaster species subgroup of the genus Drosophila (Sophophora). I. Inversion polymorphism in Drosophila melanogaster and D simulans. Proc $R$ Soc Lond Ser B 193, 137-157

Baba-Aïssa F, Solignac M (1984) La plupart des populations de Drosophila simulans ont probablement pour ancêtre une femelle unique dans un passé récent. $C R$ Acad Sci Paris Série III 299, 289-292

Begun DJ, Aquadro CF (1991) Molecular population genetics of the distal portion of the X chromosome in Drosophila: evidence for genetic hitchiking of the yellowachaete region. Genetics 129, 1147-1158

Brookfield JFY, Montgomery E, Langley CH (1984) Apparent absence of transposable element related to $P$ elements of $D$ melanogaster in other species of Drosophila. Nature (Lond) 310, 330-332

Capy P (1987) Variabilité génétique des populations naturelles de Drosophila melanogaster et Drosophila simulans. PhD Thesis Université de Paris XI, Orsay, France

Capy P, David JR, Allemand R, Carton Y, Febvay G, Kermarec A (1986) Genetic analysis of Drosophila melanogaster in the French West Indies and comparison with populations from other part of the world. Genetica 69, 167-176

Capy P, David JR, Carton Y, Pla E, Stockel J (1987) Grape breeding Drosophila communities in southern France: short range variation in ecological and genetical structure of natural populations. Acta Oecol Oecol Gen 8, 435-440

Capy P, David JR, Robertson A (1988) Thoracic trident pigmentation in natural population of Drosophila simulans: a comparison with $D$ melanogaster. Heredity 61 , 263-268

Capy P, Pla E, David JR (1994) Phenotypic and genetic variability of morphometrical traits in natural populations of Drosophila melanogaster and $D$ simulans. II. Within population variability Genet Sel Evol, 26 (in press)

Cavicchi S, Guerra D, Giogi G, Pezzoli C (1985) Temperature-related divergence in experimental populations of Drosophila melanogaster. I. Genetic and developmental basis of wing size and shape variation. Genetics 109, 665-689

Choudhary M, Singh RS (1987) A comprehensive study of genic variation in natural populations of Drosophila melanogaster. III Variations in genetic structure and their causes between Drosophila melanogaster and Drosophila simulans. Genetics 117, 697-710 
Choudhary M, Coulthart MB, Singh RS (1992) A comprehensive study of genic variation in natural populations of Drosophila melanogaster. VI. Pattern and processes of genic divergence between $D$ melanogaster and its sibling, Drosophila simulans. Genetics 130, 843-853

Cobb M, Connolly K, Burnet B (1985) Courtship behaviour in the melanogaster species sub-group of Drosophila. Behaviour 95, 203-231

Cobb M, Burnet B, Connolly K (1986) The structure of courtship in the Drosophila melanogaster species sub-group. Behaviour $95,182-212$

Cobb M, Connolly K, Burnet B (1987) The relationship between locomotor activity and courtship in the melanogaster species sub-group of Drosophila. Anim Behav 35, 705-713

David JR (1979) Utilization of morphological traits for the analysis of genetic variability in wild populations. Aquilo Ser Zool. 20, 49-61

David JR, Bocquet C (1975) Evolution in a cosmopolitan species: genetic latitudinal clines in Drosophila melanogaster wild populations. Experientia 31, 164-166

David JR, Capy P (1982) Genetics and origin of Drosophila melanogaster population recently introduced to the Seychelles islands. Genet Res 40, 295-303

David JR, Capy P (1983) Drosophila community in domestic habitats of Martinique island, and some specialized breeding sites of native species. Acta Oecol Oecol Gen $4,265-270$

David JR, Capy P (1988) Genetic variation of Drosophila melanogaster natural populations. Trends in Genet 4, 106-111

David JR, Clavel MF (1965) Interaction entre le génotype et le milieu d'élevage. Conséquences sur les caractéristiques du développement de la Drosophile. Bull Biol Fr Belg 99, 369-378

David JR, Bocquet C, Pla E (1976) New results on the genetic characteristics of the Far East race of Drosophila melanogaster. Genet Res 28, 253-260

David JR, Bocquet C, De Scheemaeker-Louis M (1977) Latitudinal adaptation of Drosophila melanogaster. New discriminative biometrical traits between European and Equatorial African populations. Genet Res 30, 247-255

David JR, Allemand R, Van Herrewege J, Cohet Y (1983) Ecophysiology: abiotic factors. The Genetics and Biology of Drosophila (M Ashburner, HL Carsons, JN Jr Thompson, eds). Academic Press, Lond Vol 3d, 105-170

Dowsett AP Young MW (1982) Differing levels of dispersed repetitive DNA among closely related species of Drosophila. Proc Natl Acad Sci USA 79, 4570-4574

Hale LR, Singh RS (1985) Mitochondrial DNA variation in natural populations of $D$ melanogaster and $D$ simulans. Genetics 110 , s42

Hyytia P, Capy P, David JR, Singh RS (1985) Enzymatic and quantitative variation in European and African populations of Drosophila simulans. Heredity 54, 209-217 Inoue YH, Yamamoto MT (1987) Insertional DNA and spontaneous mutation at the white locus in Drosophila simulans. Mol Gen Genet 209, 94-100

Jallon JM, David JR (1987) Variation in cuticular hydrocarbons among the eight species of the Drosophila melanogaster subgroup. Evolution 41, 294-302

Kawanishi M, Watanabe TK (1981) Genes affecting courtship song and mating preference in Drosophila melanogaster, Drosophila simulans and their hybrids. Evolution 35, 1128-1133 
Lachaise D, Cariou ML, David JR, Lemeunier F, Tsacas L, Ashburner M (1988) Historical biogeography of Drosophila melanogaster species subgroup. Evol Biol 22, 159-225

Lemeunier F, David JR, Tsacas L, Ashburner M (1986) The melanogaster species group. The Genetics and Biology of Drosophila (M Ashburner, HL Carson, JN Jr Thompson, eds) Academic Press, London Vol. 3B, 148-239

Louis J (1983) Les espèces dominantes de Drosophila dans les peuplements de l'Europe atlantique et méditerranéenne (Dipt.: Drosophilidae). Ann Soc Entomol Fr 19, 167-173

MacArthur RC, Wilson EO (1967) The Theory of Island Biogeography. Princeton Univ Press, Princeton, USA

Mackay TFC (1984) Jumping genes meet abdominal bristles: hybrid dysgenesisinduced quantitative variation in Drosophila melanogaster. Genet Res 44, 231-237

Maruyama K, Hartl DL (1991) Evolution of the transposable element mariner in Drosophila species. Genetics 128, 319-329

McClintock B (1984) The significance of responses of the genome to challenge. Science 226, 792-801

McDonald JF, Strand DJ, Lambert ME, Weinstein IB (1987) The responsive genome: evidence and evolutionary implications. Development as Evolutionary Process (Rauff R, Rauff E eds) Alan R. Liss Press, NY

Milkman R, Zeitler RR (1974) Concurrent multiple paternity in natural and laboratory populations of Drosophila melanogaster. Genetics 78, 1191-1193

Ohnishi S, Leigh Brown AJ, Voelker RA, Langley CH (1982) Estimation of genetic variability in natural populations of $D$ simulans by two dimensional and starch gel electrophoresis. Genetics 100, 127-136

Parsons PA (1983) The evolutionary biology of colonizing species. Camb Univ Press Pignatelli P, Mackay TFC (1989) Hybrid dysgenesis-induced response to selection in Drosophila melanogaster. Genet Res 54, 183-195

Prevosti A, Serra L, Ribo G, Aguade M, Sagarra E, Monclus M, Pilar-Garcia M (1985) The colonization of Drosophila subobscura in Chile. II. Cline in the chromosomal arrangements. Evolution 39, 838-844

Rouault J, David JR (1982) Evolutionary biology of Drosophila melanogaster and $D$ simulans: a behavioral divergence in microhabitat selection. Acta Oecol Oecol Gen 3, 331-338

Shrimpton A, Robertson A (1988a) The isolation of polygenic factors controlling bristle score in Drosophila melanogaster. I. Allocation of the third chromosome sternopleural bristle effects to chromosome sections. Genetics 118, 437-443

Shrimpton A, Robertson A (1988b) The isolation of polygenic factors controlling bristle score in Drosophila melanogaster. II. Distribution of the third chromosome bristle effects within chromosome sections. Genetics 118, 445-459

Singh RS (1989) Population genetics and evolution of species related to Drosophila melanogaster. Annu Rev Genet 23, 425-453

Singh RS, Long AD (1992) Geographic variation in Drosophila: From molecules to morphology and back. TREE 7, 340-345

Singh RS, Choudhary M, David JR (1987) Contrasting patterns of geographic variation in the cosmopolitan sibing species Drosophila melanogaster and $D$ simulans. Biochem Genet 25, 27-40 
Solignac M, Monnerot M (1986) Race formation, speciation and introgression within Drosophila simulans and $D$ sechellia inferred from mitochondrial DNA analysis. Evolution 40, 531-539

Sturtevant AH (1919) A new species closely resembling Drosophila melanogaster. Psyche (Camb) 26, 153-155

Tantawy AO Mallah GS (1961) Studies on natural populations of Drosophila. I. Heat resistance and geographical variation in Drosophila melanogaster and $D$ simulans. Evolution 15, 1-14

Taylor CE, Condra C (1980) $r$ - and $K$-selection in Drosophila pseudoobscura. Evolution 34, 1183-1193

Teissier G (1957) Discriminative biometrical characters in French and Japanese Drosophila melanogaster. Proc of the International Genetics Symposium. Tokyo, Kyoto, Japan. Cytologia (suppl), 502-505

Watada M, Ohba S, Tobari Y (1986) Genetic differentiation in Japanese populations of Drosophila simulans and $D$ melanogaster. II. Morphological variation. Jpn J Genet 61 , 469-480

Watanabe TK, Kawanishi M (1976) Colonization of Drosophila simulans in Japan. Proc Jpn Acad 52, 191-194

World Meteorological Organization (1982) Climatological normals (Clino) for climate and climate-ship stations for the period of 1931-1960. Geneva 